\title{
Food and nutrient intakes and K-ras mutations in exocrine pancreatic cancer
}

\begin{abstract}
Eva Morales, Miquel Porta, Jesús Vioque, Tomàs López, Michelle A Mendez, José Pumarega, Núria Malats, Marta Crous-Bou, Joy Ngo, Juli Rifà, Alfredo Carrato, Luisa Guarner, Josep M Corominas, Francisco X Real, for the PANKRAS II Study Group*
\end{abstract}

J Epidemiol Community Health 2007;61:641-649. doi: 10.1136/jech.2007.060632

See end of article for authors' affiliations

Correspondence to: Professor M Porta, Clinical \& Molecular Epidemiology of Cancer Unit, Institut Municipal d'Investigació Mèdica (IMIM), Universitat Autònoma de Barcelona, Carrer del Dr Aiguader 88, E-08003 Barcelona, Spain; mporta@imim.es

Accepted for publication 31 March 2007

\begin{abstract}
Background: No studies have investigated the relation between K-ras mutations and dietary factors in exocrine pancreatic cancer (EPC), and fewer than 10 studies have done so in other neoplasms.

Patients and Methods: Incident cases of EPC were prospectively identified, and interviewed face-to-face during hospital admission. Food and nutrient intakes were measured with a food frequency questionnaire. Logistic regression was used to compare EPC cases $(n=107)$ with and without K-ras mutations (case-case study).

Results: K-ras mutations were more common among daily consumers of milk and other dairy products than among non-daily consumers: the odds ratio adjusted by total energy, age, sex, smoking, alcohol and coffee consumption (ORa) was 5.1 (95\% Cl 1.1 to $24.5, \mathrm{p}=0.040$ ). For all dairy products, including butter, the ORa for the medium and upper tertiles of intake were 5.4 and 11.6 , respectively ( $p$ for trend $=0.023$ ). The ORa for regular coffee drinkers further adjusted by dairy consumption was 4.7 (95\% $\mathrm{Cl} 1.1$ to $20.7, \mathrm{p}=0.043$ ). K-ras mutated cases reported a lower intake of vitamin $\mathrm{E}(\mathrm{ORa}=0.2, \mathrm{p}$ for trend $=0.036)$, polyunsaturated fats and omega 3 fatty acids $(\mathrm{ORa}=0.2 ; \mathrm{p}$ for trend $<0.03)$.

Conclusions: Results support the hypothesis that in EPC exposure to specific dietary components or
\end{abstract} contaminants may influence the occurrence or persistence of K-ras mutations.
A lthough the aetiology of exocrine pancreatic cancer (EPC) is poorly understood, important pathogenic clues have emerged from epidemiological and genetic studies. ${ }^{1-4}$ The classic risk factors include age, male sex, cigarette smoking, and possibly diabetes and chronic pancreatitis. The only firmly established and modifiable risk factor is smoking, but it explains only a fraction of the incidence. ${ }^{1}$

Diet may also play a role in modifying risk of pancreatic cancer. Some studies found intake of fresh fruits, vegetables, fibre, vitamins C and D, carotenes and folate to be protective, whereas high caloric intake, dairy products, eggs, fats, carbohydrates and cholesterol have been seen to increase risk. However, the consistency of findings, specific dietary components and mechanisms remain unclear. ${ }^{5-9}$

Molecular pathology and molecular epidemiology studies suggest that wild-type K-ras EPC arise though genetic pathways distinct from those that harbour a K-ras mutation. ${ }^{12} 1011$ These somatic (acquired) mutations are the most frequent oncogene alteration in human cancers, and a prime example of activation by point mutation. ${ }^{11}{ }^{12}$ Ras proteins are critical regulators of cell function, including growth, differentiation and apoptosis, with membrane localisation of the protein being a prerequisite for malignant transformation, which promotes tumour proliferation, survival and invasion. ${ }^{4}{ }^{12}{ }^{13} \mathrm{~K}$-ras point mutations at codon 12 , an early event in pancreatic carcinogenesis, are found in $75 \%-90 \%$ of pancreatic cancers, a frequency not encountered in any other solid neoplasm. ${ }^{10-13}$ As early as 1983, mutated ras oncogenes were identified in experimental tumours of rodents that were exposed to chemical or physical carcinogens. ${ }^{12}$ Evidence that ras genes can be involved in the initiation of carcinogenesis was obtained in 1985 when it was shown that $\mathrm{H}$-ras oncogenes that were activated in chemically induced mammary carcinomas of rats were activated by the type of mutation that is known to be caused by the initiating carcinogen. ${ }^{12}{ }^{14}$ Therefore, laboratory experiments have shown that ras genes are critical DNA targets for chemical carcinogens. ${ }^{3}{ }^{12}$ Molecular epidemiological studies have suggested that in pancreatic cancer coffee $e^{15-18}$ and some environmental compounds $^{1-3} 101417$ might be associated with K-ras mutations; however, clinical and environmental processes with the potential to influence the occurrence and persistence of K-ras mutations in human neoplasms are still poorly understood. ${ }^{3}$

Studies in animals and humans suggest that dietary factors regulate the development of neoplasms through their effects on $\mathrm{K}$-ras mutations. In colorectal tumours K-ras mutations have been associated with intake of cruciferous vegetables, meat, coffee, carbohydrates, monounsaturated and other dietary fats, vitamins B6 and B12, calcium, animal proteins and dietary folate; ${ }^{19-26}$ the associations are often weak and inconsistent. ${ }^{1}$ A lung carcinogenesis study in mice showed that a diet supplemented with vitamin $\mathrm{E}$ decreased the frequency of $\mathrm{K}$ ras mutations. ${ }^{27}$

Despite the firmly established importance of K-ras mutations in the aetiopathogenesis of EPC, and the potential role of dietary components in modifying risk, the relation between diet and K-ras mutations has so far not been studied in this disease, and seldom in other neoplasms. The objective of the present study was therefore to analyse the relation between food and nutrient intakes and the prevalence at diagnosis of mutations in codon 12 of the K-ras oncogene in patients with EPC.

Abbreviations: EPC, exocrine pancreatic cancer; MUFA, monounsaturated fat; PANKRAS II, Multicentre Prospective Study on the Role of K-ras and other Genetic Alterations in the Diagnosis, Prognosis and Aetiology of Pancreatic and Biliary Diseases; PUFA, polyunsaturated fat; $R E$, retinol equivalents (1 RE $=1 \mu \mathrm{g}=5 \mathrm{IU}$ of vitamin $A) ; S F F Q$, semiquantitative food frequency questionnaire 
PATIENTS AND METHODS

\section{Selection of patients}

Methods of the PANKRAS II study have been described in detail. ${ }^{10}{ }^{14-16}{ }^{28-30}$ Briefly, subject recruitment took place in 19925 at five general hospitals in the eastern Mediterranean part of Spain, where 185 incident cases of EPC were prospectively identified. All their diagnoses were reviewed by a panel of experts and by the study reference pathologists, blinded to the original diagnoses and to molecular results.

Mutations in codon 12 of the K-ras gene could be tested for 121 cases, of whom 94 (77.7\%) had mutations, and 27 did not. ${ }^{1014-16}$ The present report is based on 107 EPC patients with known K-ras status, and with information about dietary habits and potential confounders. There were no significant differences between them and the remaining EPC cases with respect to sex, education, study site, tumour stage, duration of the interview, energy intake and consumption of coffee, tobacco and alcohol, except that the included subjects were slightly younger. ${ }^{15}$ The mean age of the 107 cases was 64.2 years (range $36.8-88.6), 42.1 \%$ were female, 83 (77.6\%) harboured a K-ras mutation and 24 did not. ${ }^{14-16}$ There were no differences in the frequency of mutations according to age, sex, education and tumour stage at diagnosis. Wild-type cases had smoked slightly more and drank significantly less coffee than mutated cases. ${ }^{15}$ The study design was approved by the ethics committees of the participating hospitals, and patients gave informed consent to be included in the study.

\section{Patient interviews and information on diet}

A structured form was used to collect clinicopathological information from medical records, including details on diagnostic procedures, laboratory results and follow-up care..$^{29}$ Over $88 \%$ of the patients were interviewed face-to-face by trained monitors during hospital stay, close to the time of diagnosis. The respondent was the patient himself in $96 \%$ of the cases and a relative alone in $4 \%$. Interviews included questions about past clinical history, symptoms, occupation, diet, coffee, alcohol and tobacco consumption. ${ }^{10}{ }^{15} 2930$ Information was thus obtained on dietary habits. Patients were asked about the frequency of consumption of food groups during the year before the first symptom of the current illness. For this purpose a brief food frequency questionnaire (bFFQ) was administered; it consisted of 14 selected indicator food groups: milk and other dairy products, excluding butter; butter; eggs; red meat, chicken and organs; fish and shellfish; raw vegetables; cooked vegetables; fruit; bread; potatoes; cereals and legumes; sausage and cured meats; lard; and vegetable oil. In the bFFQ the frequency of consumption was divided into four categories: rarely or never; various times/month; various times/week; and daily, with an additional category of "don't know/remember". $^{28}{ }^{30}$ To assess the reliability of interviews, a sample of relatives was concurrently and separately interviewed about the patient's clinical history and dietary habits, and agreement between the two sets of responses was compared. ${ }^{30}$

To estimate energy and nutrient content values for the food groups assessed in the PANKRAS study, we used data from a validated 93-item semi-quantitative food frequency questionnaire (SFFQ) with nine response categories administered to participants $(n=1337)$ in a nutrition and health populationbased survey carried out in an area with dietary habits comparable to areas included in the PANKRAS study. ${ }^{31}$ Nutrient intakes were calculated by multiplying the frequency of use for each food by the nutrient composition for the portion size specified on the SFFQ, summing across all foods to obtain total intakes for each individual. ${ }^{28}$ The SFFQ appeared adequate for ranking subjects according to intake of most food groups and nutrients. ${ }^{28}$ Correlations between actual and simulated intakes exceeded 0.70 for 10 of the groups assessed. Estimated intakes for four of the 14 food groups (milk and other dairy products, fresh vegetables, bread, and fruit) were more moderate (0.43-0.56). Correlations exceeded 0.60 for most nutrients. ${ }^{28}$

\section{Detection of K-ras mutations}

Details of laboratory protocols have also been described elsewhere..$^{1014}{ }^{15}$ Briefly, mutations in codon 12 of the K-ras oncogene were studied using DNA extracted from paraffinembedded tumour tissue. DNA was extracted and amplified in two steps by nested PCR; in the second amplification reaction, an artificial BstNI restriction endonuclease site was introduced to discriminate between wild-type and mutated K-ras codon 12 sequences. Products were analysed by acrylamide gel electrophoresis and ethidium bromide staining. This technique is able to detect one homozygous mutated cell in the presence of $10^{2}$ normal cells. To characterise the nucleotide substitution in codon 12, all mutated samples were further analysed using an RFLP-based approach. Interpretation of digestion products electrophoresis was performed independently by three investigators. When discordant results were obtained, the analysis was repeated and results evaluated again.

\section{Statistical analyses}

In this case-case study ${ }^{32}$ we compared the dietary habits of the 83 cases of EPC with a K-ras mutated tumour and of the 24 cases of EPC whose tumours did not harbour such mutations. In the case-case design the odds ratio is a measure of geneenvironment interaction; in our study, specifically, the interaction between dietary components and somatic mutations in the K-ras (proto)oncogene. ${ }^{14}{ }^{15}{ }^{32}$ Categories of frequency of consumption for food groups were grouped as low, medium and high as shown below. All nutrients intakes were adjusted for total energy intake by calculating the residuals from a linear regression with the $\log (\mathrm{e})$ of the nutrient modelled as the dependent variable and the $\log (\mathrm{e})$ of total energy intake as the independent variable. ${ }^{33}$ Univariate statistics were computed as customary. ${ }^{34-36}$ Student's t test or Mann-Whitney U test were used to analyse normally or non-normally distributed quantitative variables, respectively. In contingency tables, Fisher's exact test for homogeneity or independence was applied to assess the relation between two categorical variables. When a tendency was observed Mantel-Haenszel's $\chi^{2}$ test for linear trend was used. To estimate the magnitude of the associations between food group or nutrient intakes and K-ras mutations multivariate-adjusted odds ratios and their corresponding 95\% confidence intervals (CI) were calculated by unconditional logistic regression. ${ }^{32} 36$ Categorical ordinal variables were analysed for a linear dose-response relation through the multivariate analogue of Mantel's extension test using the likelihood ratio test with one degree of freedom. When a tendency was not clearly apparent, the likelihood ratio test statistic was used to asses significance. The likelihood ratio test was also applied to explore the joint effect of two variables by including in the model the two main terms and the interaction term between the two variables. ${ }^{34-36}$ The following potential confounders were included in the basic models: age (continuous), gender, total energy intake (kcal/day, continuous), coffee consumption (non-regular and regular drinkers), smoking (never-, former- and current-smokers), and alcohol consumption (non-drinkers and drinkers). Allowance for other possible confounding variables did not materially alter the estimates. The level of statistical significance was set at 0.05 , and all tests are two-tailed. Statistical analyses were performed using SPSS, version 12.0 (SPSS Inc, Chicago, IL, USA). 


\section{RESULTS}

Daily consumers of milk and other dairy products were over five times more likely to have a K-ras mutated tumour than nondaily consumers: the odds ratio adjusted by total energy, age and sex was 6.30 (95\% CI 1.56 to 25.41). The OR further adjusted by smoking and alcohol consumption was 7.58 (95\% CI 1.73 to 33.25). Patients in the upper category of butter consumption were over three times more likely to have a K-ras mutated tumour. For all dairy products, including butter, the ORs for the medium and high categories of intake were 7.43 and 19.68, respectively ( $p$ for trend $=0.002$ ) (table 1$)$.

No statistically significant associations were observed between the rest of food groups and K-ras mutations, except that the intake of meat and sausages combined was higher among cases with wild-type K-ras tumours. However, weaker associations were also apparent with vegetables and fruits combined (ORs for medium and high tertiles of intake were 0.44 and 0.28 , respectively, $\mathrm{p}$ for trend $=0.083$ ), fish (OR for high tertile $=0.36,95 \%$ CI 0.06 to 2.09), and vegetable oil (ORs for medium and high tertiles: 0.57 and 0.24 , respectively, $\mathrm{p}$ for trend $=0.182$ ) (table 1 ).

Table 2 presents the mutually-adjusted relations of dairy products and coffee consumption with K-ras mutations. Even after adjusting by coffee consumption, daily consumers of milk and other dairy products were five times more likely to have a $\mathrm{K}$-ras mutated EPC than non-daily consumers (OR $=5.10$, $p=0.040)$. The ORs for the medium and high categories of all dairy products were over 5 and 11 , respectively ( $p$ for trend $=0.023$ ). Our previous report on coffee did not take diet into account; ${ }^{15}$ now, after adjusting by milk and other dairy products, regular coffee drinkers were still over four times more likely to have a K-ras mutated tumour than non-regular coffee drinkers $(p<0.05)$. Furthermore, the odds ratios increased with increasing number of coffee cups ( $p$ for trend $=0.034$ ) (table 2 ). There was no evidence of an interaction between dairy products and coffee. After adjusting for calcium intake the estimates for dairy products were significantly increased, while for coffee they remained unchanged.

There were no significant differences between mutated and wild-type cases in total energy intake, or in the intakes of total proteins, total fats and carbohydrates (table 3). Mutated cases had a lower intake of polyunsaturated fats (PUFAs) and omega 3 fatty acids (ORs for lowest tertile of intake $=0.19$; $p$ for trend $<0.03$ ). No significant associations were observed with saturated fats, cholesterol, monounsaturated fats (MUFAs) and omega 6 fatty acids.

Regarding antioxidant dietary components, mutated patients had a lower intake of vitamin E: the adjusted ORs for medium and high tertiles were 0.42 and 0.24 , respectively ( $p$ for trend $=0.036$ ). Although statistically non-significant, intakes of total carotene and vitamin $\mathrm{C}$ were also lower among mutated cases. There was no statistically significant association between the reported intake of vitamin D and K-ras status. Concerning the dietary methyl donors examined (vitamin B6, vitamin B12 and folate), intake of vitamin B6 was also lower among mutated cases. No association was observed with folate. The energy-, age- and sex-adjusted ORs for the medium and high categories of calcium intake were 2.85 and 3.79, respectively ( $p$ for trend $=0.030$ ) (table 3 ). When milk and other dairy products were included in the model the calcium ORs became attenuated and statistically non-significant. This was also the case when the ORs for calcium were adjusted for coffee. Inclusion in the model of other food groups and nutrients did not materially modify these estimates.

\section{DISCUSSION}

Patients with a K-ras mutated tumour reported a higher intake of dairy products, and lower intakes of vitamin E, PUFAs and omega 3 fatty acids than patients with K-ras wild-type tumours. Dietary factors were hence differentially related with K-ras mutated and K-ras wild-type EPC. These findings support the notion of aetiological heterogeneity of pancreatic cancer. ${ }^{10}{ }^{11}$

The occurrence of pancreatic cancer may be influenced by environmental factors. ${ }^{1-3}$ Dietary factors are among possible causal agents, although findings are inconsistent, and dietary components and biological mechanisms remain unclear. $^{5-9}$ Disagreement among studies might partly be due to the fact that they analysed all cases of pancreatic cancer combined; it is likely, however, that wild-type K-ras EPC arise through pathways distinct from tumours that harbour K-ras mutations. ${ }^{1-4}$ 10-12 $^{12}$

The association between K-ras mutations and dairy products might be coherent with previously unconnected and still tentative findings on diet, organochlorine compounds and pancreatic cancer. ${ }^{1337}$ A positive association between butter and saturated-fat intake and pancreatic cancer risk was found in a prospective study in Finland, ${ }^{38}$ a case-control study in Louisiana also found a positive relation with consumption of dairy foods. ${ }^{39}$ However, inverse and null effects of dairy products were seen in other traditional studies, and the risk associated with fat intake was inconsistent. ${ }^{540}{ }^{41}$ Fat foods are known to contain highly lipophilic environmental chemical agents, including organochlorine compounds; some $80-90 \%$ of human exposure to organochlorines occurs through food, including butter and other dairy products..$^{42-52}$ Some organochlorines have been associated with risk of pancreatic cancer ${ }^{153}$ and with K-ras mutations in exocrine pancreatic cancer. ${ }^{10}$ Given the age of most patients in our study, it is likely that the intake of dairy products quantified by our questionnaire was correlated with intake at the time when organochlorines were commonly present in these foods. Although use of organochlorine pesticides was restricted in Spain in the early 1980s, recent studies continue to find organochlorine residues in dairy products and other food groups. ${ }^{1045-52}$

We previously reported that pancreatic cancer patients with mutations in K-ras drank more coffee than cases without a mutation, with a dose-response relation; ${ }^{15}$ these analyses did not include dietary information. Jacobsen and Heuch showed independently from us that our results were "consistent with an overall lack of association between coffee drinking and the risk of pancreatic cancer" ${ }^{\prime 18}$ The conclusion of an overall lack of association and the hypothesis of an association with K-ras mutations are also supported by other lines of evidence. ${ }^{13}$ 15${ }^{18}$ 54-58 $^{5}$ Evidence for an association between coffee consumption and K-ras mutations in exocrine pancreatic cancer is also present in the study by Slebos et al: ${ }^{174}$ cases with a K-ras mutated tumour were almost three times more likely to be in the upper category of total coffee consumption than cases without a mutation (OR 2.78, p=0.11); in fact, the study ${ }^{17}$ probably suffered from biases that tended to dilute the association. ${ }^{154}$

Might coffee drinking and dairy products mutually confound their respective associations with K-ras? Not according to the results presented here: consumption of coffee and dairy products were independently associated with an increased odds of having a K-ras mutated pancreatic cancer. Furthermore, after adjusting for calcium the ORs for milk and other dairy products increased significantly, while the ORs for coffee did not change. This suggests that the association between dairy products and K-ras mutations is not confounded by calcium. It also suggests the need to consider the hypothesis that environmental contaminants might be involved. ${ }^{110}$ Furthermore, the association between calcium intake and Kras mutations was attenuated when dairy products were included in the model. Non-genotoxic or perhaps epigenetic 
Table 1 Consumption of food groups among cases of exocrine pancreatic cancer with and without mutations in the K-ras oncogene

\begin{tabular}{|c|c|c|c|c|c|c|c|c|}
\hline & \multirow[b]{2}{*}{$\begin{array}{l}\text { All cases } \\
(n=107)\end{array}$} & \multicolumn{3}{|l|}{$\mathrm{K}$-ras } & \multicolumn{2}{|l|}{ Adjusted OR† } & \multicolumn{2}{|l|}{ Adjusted OR $\ddagger$} \\
\hline & & $\begin{array}{l}\text { Mutated } \\
(n=83)\end{array}$ & $\begin{array}{l}\text { Wild-type } \\
(n=24)\end{array}$ & p Value $\S$ & OR $(95 \% \mathrm{Cl})$ & $\mathrm{p}$ Value 9 & OR $(95 \% \mathrm{Cl})$ & p Value 9 \\
\hline \multicolumn{9}{|l|}{$\begin{array}{l}\text { Milk and other dairy } \\
\text { products }^{*}\end{array}$} \\
\hline $\begin{array}{l}\text { Non-daily } \\
\text { Daily }\end{array}$ & $\begin{array}{l}18(16.8) \\
89(83.2)\end{array}$ & $10(12.0)$ & $\begin{array}{r}8(33.3) \\
16(667)\end{array}$ & 0.026 & 1.00 & 0.008 & $\begin{array}{l}1.00 \\
758(173-32525\end{array}$ & 0.005 \\
\hline \multicolumn{9}{|l|}{ Butter } \\
\hline Lowłł & $68(63.6)$ & $49(59.0)$ & 19 (79.2) & $0.063^{* *}$ & 1.00 & 0.049 & 1.00 & 0.048 \\
\hline Medium & 11 (10.3) & $9(10.8)$ & $2(8.3)$ & & $1.77(0.34-9.24)$ & & $1.74(0.32-9.40)$ & \\
\hline High & $28(26.2)$ & $25(30.1)$ & $3(12.5)$ & & $3.45(0.89-13.36)$ & & $3.59(0.90-14.51)$ & \\
\hline \multicolumn{9}{|l|}{ All dairy products } \\
\hline Low§§ & $17(15.9)$ & $9(10.8)$ & $8(33.3)$ & $0.008^{* *}$ & 1.00 & 0.003 & 1.00 & 0.002 \\
\hline Medium & $63(58.9)$ & $50(60.2)$ & $13(54.2)$ & & $6.15(1.50-25.24)$ & & $7.43(1.67-33.05)$ & \\
\hline High & $27(25.2)$ & $24(28.9)$ & $3(12.5)$ & & $15.53(2.35-102.40)$ & & $19.68(2.64-146.51)$ & \\
\hline \multicolumn{9}{|l|}{ Coffee } \\
\hline Non-regular drinker & $18(16.8)$ & $10(12.0)$ & $8(33.3)$ & 0.026 & 1.00 & 0.011 & 1.00 & 0.006 \\
\hline Regular drinker & 89 (83.2) & $73(88.0)$ & $16(66.7)$ & & $5.27(1.44-19.30)$ & & $6.99(1.71-28.66)$ & \\
\hline 0 cups per week & $18(17.1)$ & $10(12.3)$ & $8(33.3)$ & $0.038^{* *}$ & 1.00 & 0.014 & 1.00 & 0.004 \\
\hline $1-7$ cups per week & $28(26.7)$ & $22(27.2)$ & $6(25.0)$ & & $4.07(0.96-17.27)$ & & $4.30(0.92-20.08)$ & \\
\hline 8-14 cups per week & $27(25.7)$ & $22(27.2)$ & $5(20.8)$ & & $5.75(1.13-29.12)$ & & $8.75(1.48-51.57)$ & \\
\hline$\geqslant 15$ cups per week & $32(30.5)$ & $27(33.3)$ & $5(20.8)$ & & $6.33(1.39-28.88)$ & & $11.15(2.03-61.23)$ & \\
\hline Raw vegetables & & & & & & & & \\
\hline Low§乡 & $17(15.9)$ & $12(14.5)$ & $5(20.8)$ & 0.171 & 1.00 & 0.605 & 1.00 & 0.668 \\
\hline Medium & $35(32.7)$ & $31(37.3)$ & $4(16.7)$ & $0.645^{* *}$ & $3.58(0.77-16.55)$ & $0.103+t$ & $3.24(0.60-15.53)$ & $0.211 \mathrm{t \dagger}$ \\
\hline High & $55(51.4)$ & $40(48.2)$ & $15(62.5)$ & & $1.08(0.30-3.89)$ & & $1.09(0.26-4.53)$ & \\
\hline Cooked vegetables & & & & & & & & \\
\hline Low§§ & $31(29.0)$ & $28(33.7)$ & $3(12.5)$ & 0.112 & 1.00 & 0.096 & 1.00 & 0.136 \\
\hline Medium & $49(45.8)$ & $35(42.2)$ & $14(58.3)$ & $0.124^{* *}$ & $0.24(0.06-0.95)$ & $0.074 \uparrow \dagger$ & $0.20(0.05-0.92)$ & $0.077+\dagger$ \\
\hline High & $27(25.2)$ & $20(24.1)$ & $7(29.2)$ & & $0.26(0.06-1.21)$ & & $0.25(0.05-1.33)$ & \\
\hline All vegetables & & & & & & & & \\
\hline Low§§ & $46(43.0)$ & $38(45.8)$ & $8(33.3)$ & 0.493 & 1.00 & 0.228 & 1.00 & 0.369 \\
\hline Medium & $40(37.4)$ & $30(36.1)$ & $10(41.7)$ & $0.271^{* *}$ & $0.55(0.17-1.74)$ & & $0.60(0.17-2.15)$ & \\
\hline High & $21(19.6)$ & $15(18.1)$ & $6(25.0)$ & & $0.47(0.13-1.68)$ & & $0.54(0.14-2.13)$ & \\
\hline Fruits & & & & & & & & \\
\hline Low§§ & $8(7.5)$ & $7(8.4)$ & $1(4.2)$ & 0.765 & 1.00 & 0.583 & 1.00 & 0.536 \\
\hline Medium & $15(14.0)$ & $11(13.3)$ & $4(16.7)$ & $0.712^{\star *}$ & $0.39(0.04-4.41)$ & $0.706+\dagger$ & $0.38(0.03-5.08)$ & $0.705+\dagger$ \\
\hline High & 84 (78.5) & $65(78.3)$ & $19(79.2)$ & & $0.45(0.04-4.32)$ & & $0.40(0.04-4.52)$ & \\
\hline Vegetables \& fruits & & & & & & & & \\
\hline Low§§ & $33(30.8)$ & $28(33.7)$ & $5(20.8)$ & 0.397 & 1.00 & 0.173 & 1.00 & 0.219 \\
\hline Medium & $32(29.9)$ & $25(30.1)$ & $7(29.2)$ & $0.232^{* *}$ & $0.51(0.13-1.98)$ & $0.084 \uparrow \dagger$ & $0.44(0.10-1.97)$ & $0.083+\dagger$ \\
\hline High & $42(39.3)$ & $30(36.1)$ & $12(50.0)$ & & $0.31(0.08-1.22)$ & & $0.28(0.06-1.26)$ & \\
\hline Vegetable oil & & & & & & & & \\
\hline Low§§ & $7(6.5)$ & $6(7.2)$ & $1(4.2)$ & 0.888 & 1.00 & 0.320 & 1.00 & 0.182 \\
\hline Medium & $8(7.5)$ & $7(8.4)$ & $1(4.2)$ & $0.411^{* *}$ & $1.20(0.06-24.53)$ & & $0.57(0.02-15.05)$ & \\
\hline High & $92(86.0)$ & 70 (84.3) & $22(91.7)$ & & $0.46(0.05-4.38)$ & & $0.24(0.02-2.95)$ & \\
\hline Lard & & & & & & & & \\
\hline Low $\ddagger \ddagger$ & $91(85.0)$ & $72(86.7)$ & $19(79.2)$ & 0.549 & 1.00 & 0.376 & 1.00 & 0.575 \\
\hline Medium & $10(9.3)$ & $7(8.4)$ & $3(12.5)$ & $0.364^{* *}$ & $0.63(0.15-2.69)$ & & $0.61(0.12-3.12)$ & $0.807+\dagger$ \\
\hline High & $6(5.6)$ & $4(4.8)$ & $2(8.3)$ & & $0.52(0.08-3.13)$ & & $0.73(0.09-5.73)$ & \\
\hline Meat, chicken \& organs & & & & & & & & \\
\hline Low§§ & $8(7.5)$ & $7(8.4)$ & $1(4.2)$ & 0.715 & 1.00 & 0.282 & 1.00 & 0.376 \\
\hline Medium & $61(57.0)$ & $48(57.8)$ & $13(54.2)$ & $0.377^{* *}$ & $0.52(0.06-4.74)$ & & $0.83(0.08-8.07)$ & \\
\hline High & 38 (35.5) & $28(33.7)$ & $10(41.7)$ & & $0.33(0.03-3.40)$ & & $0.48(0.04-5.32)$ & \\
\hline Sausages \& cured meats & & & & & & & & \\
\hline Low§§ & $35(32.7)$ & $30(36.1)$ & $5(20.8)$ & 0.369 & 1.00 & 0.109 & 1.00 & 0.147 \\
\hline Medium & $36(33.6)$ & $27(32.5)$ & $9(37.5)$ & $0.176^{* *}$ & $0.48(0.14-1.65)$ & & $0.40(0.11-1.53)$ & \\
\hline High & $36(33.6)$ & $26(31.3)$ & $10(41.7)$ & & $0.34(0.09-1.31)$ & & $0.35(0.08-1.54)$ & \\
\hline Meat \& sausages & & & & & & & & \\
\hline Low§§ & $27(25.2)$ & $23(27.7)$ & $4(16.7)$ & 0.207 & 1.00 & 0.027 & 1.00 & 0.021 \\
\hline Medium & $39(36.4)$ & $32(38.6)$ & $7(29.2)$ & $0.086^{* *}$ & $0.68(0.17-2.73)$ & & $0.53(0.11-2.45)$ & \\
\hline High & 41 (38.3) & $28(33.7)$ & $13(54.2)$ & & $0.21(0.05-0.93)$ & & $0.15(0.03-0.86)$ & \\
\hline Fish \& shellfish & & & & & & & & \\
\hline Low§§ & $27(25.2)$ & $21(25.3)$ & $6(25.0)$ & 0.466 & 1.00 & 0.465 & 1.00 & 0.380 \\
\hline Medium & $69(64.5)$ & $55(66.3)$ & $14(58.3)$ & $0.525^{* *}$ & $1.08(0.36-3.25)$ & $0.467+\dagger$ & $1.05(0.31-3.53)$ & $0.179+\dagger$ \\
\hline High & 11 (10.3) & $7(8.4)$ & $4(16.7)$ & & $0.43(0.08-2.21)$ & & $0.36(0.06-2.09)$ & \\
\hline Eggs & & & & & & & & \\
\hline Low 9 & $41(38.3)$ & $33(39.8)$ & $8(33.3)$ & 0.639 & 1.00 & 0.537 & 1.00 & 0.702 \\
\hline High & $66(61.7)$ & $50(60.2)$ & $16(66.7)$ & & $0.74(0.28-1.95)$ & & $0.81(0.28-2.34)$ & \\
\hline Bread & & & & & & & & \\
\hline Non-daily & $5(4.7)$ & $3(3.6)$ & $2(8.4)$ & 0.312 & 1.00 & 0.356 & 1.00 & 0.363 \\
\hline Daily & $102(95.3)$ & $80(96.4)$ & $22(91.7)$ & & $2.63(0.36-19.36)$ & & $2.94(0.30-29.27)$ & \\
\hline Potatoes & & & & & & & & \\
\hline Low§§ & $10(9.3)$ & $6(7.2)$ & $4(16.7)$ & 0.263 & 1.00 & 0.722 & 1.00 & 0.311 \\
\hline Medium & $47(43.9)$ & $39(47.0)$ & $8(33.3)$ & $0.730^{* *}$ & $3.44(0.73-16.10)$ & $0.271+\dagger$ & $3.76(0.66-21.37)$ & $0.321 \mathrm{t \dagger}$ \\
\hline High & $50(46.7)$ & $38(45.8)$ & $12(50.0)$ & & $2.17(0.40-11.62)$ & & $3.80(0.56-25.90)$ & \\
\hline
\end{tabular}


Table 3 Energy-adjusted nutrient consumption in exocrine pancreatic cancer cases with and without K-ras mutations. Tertiles of energy-adjusted intakes of nutrients

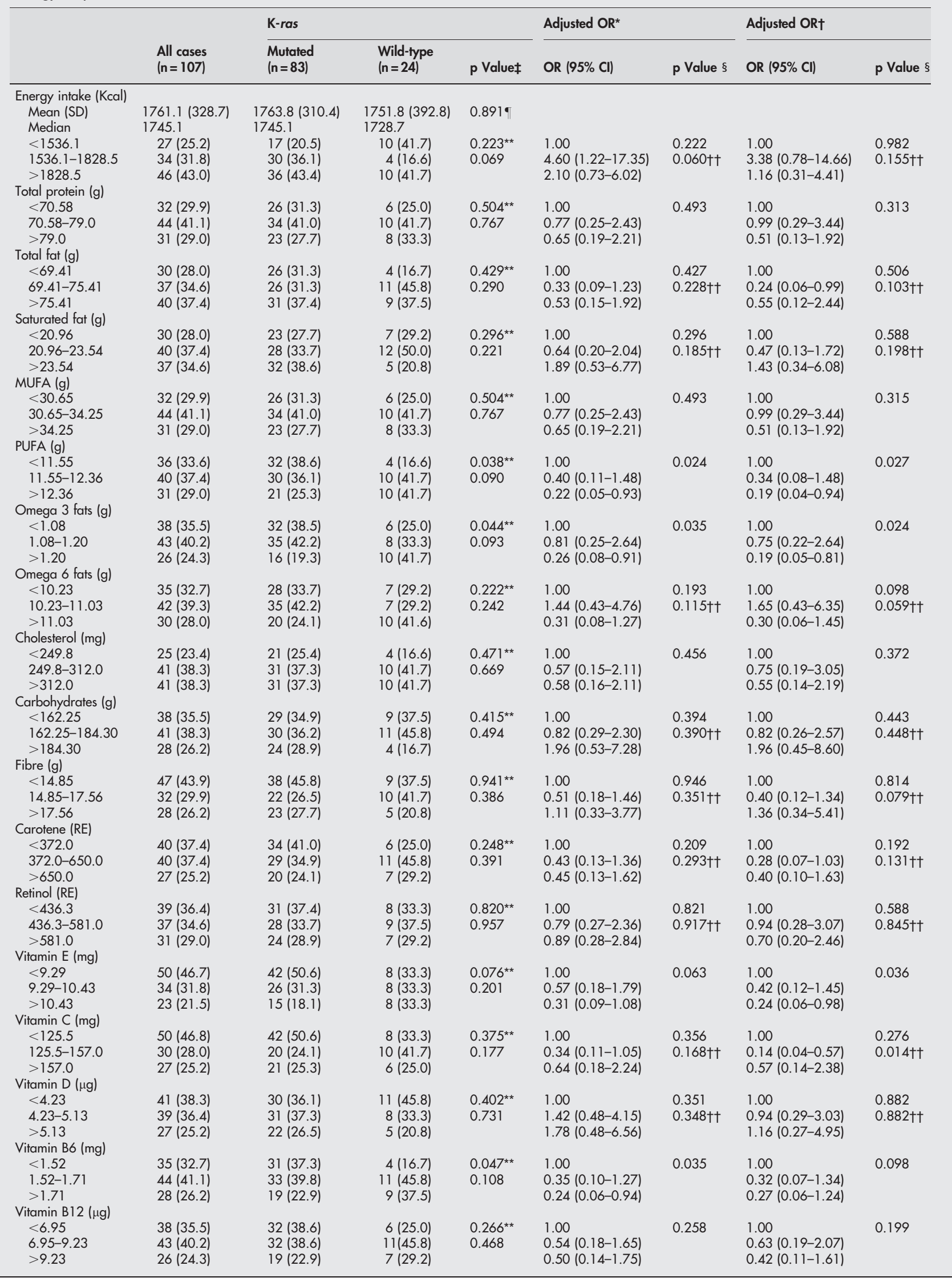


Table 3 Continued

\begin{tabular}{|c|c|c|c|c|c|c|c|c|}
\hline & \multirow[b]{2}{*}{$\begin{array}{l}\text { All cases } \\
(n=107)\end{array}$} & \multicolumn{3}{|l|}{ K-ras } & \multicolumn{2}{|l|}{ Adjusted OR* } & \multicolumn{2}{|l|}{ Adjusted OR† } \\
\hline & & $\begin{array}{l}\text { Mutated } \\
(n=83)\end{array}$ & $\begin{array}{l}\text { Wild-type } \\
(\mathrm{n}=24)\end{array}$ & p Valueł & OR $(95 \% \mathrm{Cl})$ & $p$ Value $\S$ & OR $(95 \% \mathrm{Cl})$ & $p$ Value $\S$ \\
\hline \multicolumn{9}{|l|}{ Folate $(\mu \mathrm{g})$} \\
\hline$<235.0$ & $43(40.2)$ & $33(39.8)$ & $10(41.6)$ & $0.917^{* *}$ & 1.00 & 0.905 & 1.00 & 0.862 \\
\hline $235.0-282.35$ & $36(33.6)$ & 29 (34.9) & $7(29.2)$ & 0.876 & $1.25(0.41-3.79)$ & $0.865+\dagger$ & $0.77(0.22-2.73)$ & $0.923+\dagger$ \\
\hline$>282.35$ & $28(26.2)$ & $21(25.3)$ & $7(29.2)$ & & $0.90(0.30-2.76)$ & & $0.91(0.26-3.15)$ & \\
\hline \multicolumn{9}{|l|}{ Calcium (mg) } \\
\hline$<778.0$ & $43(40.2)$ & $29(34.9)$ & $14(58.3)$ & $0.070^{* *}$ & 1.00 & 0.030 & 1.00 & 0.166 \\
\hline $7778.0-927.9$ & 38 (35.5) & $32(38.6)$ & $6(25.0)$ & 0.145 & $2.85(0.93-8.77)$ & & $1.69(0.49-5.82)$ & \\
\hline$>927.9$ & $26(24.3)$ & $22(26.5)$ & $4(16.7)$ & & $3.79(0.91-15.87)$ & & $2.87(0.60-13.75)$ & \\
\hline
\end{tabular}

Values in parentheses are column percentages.

$\mathrm{RE}$, retinol equivalents ( $1 \mathrm{RE}=1 \mu \mathrm{g}=5 \mathrm{IU}$ of vitamin A)

*Odds ratio adjusted for total energy, age and sex.

†Odds ratio adjusted for total energy, age, sex, smoking, alcohol and coffee.

łUnless otherwise specified, $p$ value derived from Fisher's exact test.

$\S$ Unless otherwise specified, $\mathrm{p}$ value derived from multivariate analogue of Mantel's extension test for linear trend.

- Student's t test.

**Mantel-Haenszel's $\chi^{2}$ test for linear trend.

t+likelihood ratio test

expression, ${ }^{68}{ }^{69}$ which is in accordance with findings in the present study. Dietary fats are thought to modulate ras functions during the promotion and progression of colon cancer, resulting in decreased expression of ras. ${ }^{68} 70$ Other molecular mechanisms may contribute to the benefits of omega-3 fatty acids, including limitation of tumour cell proliferation, increase of apoptosis, promotion of cell differentiation, modulation of ras proteins and protein kinase $\mathrm{C}$ activity, and possibly limitations of angiogenesis. ${ }^{3} 7172$

Clearly, some of our estimates were statistically imprecise. This was largely because of the small number of K-ras wild-type cases, a consistent finding in EPC..$^{1-3}$ Also, a relatively high number of dietary factors were compared. Hence, both false negatives and false positives may have occurred. Nonetheless, the direction of the association with K-ras status was largely consistent for food groups and nutrients that are commonly correlated (for example, PUFA and vegetables and fruits, calcium and dairy products). Although undoubtedly small, to date this is the largest study with environmental and genetic information in pancreatic cancer, and only one of two such studies based on personal interviews with patients ${ }^{16}{ }^{17}$; the other study included 61 cases (15 K-ras wild-type cases and $46 \mathrm{~K}$-ras mutated cases). ${ }^{17}$ Ours is the first study to analyse diet and K-ras activation in human pancreatic cancer, and one of fewer than 10 on ras mutations and diet in all cancers. We achieved a high response rate, and over $80 \%$ of patients were interviewed during hospital stay, near the time of diagnosis. The proportion of cases with both genetic and dietary data is also high for EPC. ${ }^{54}$ Lack of differences between patients included and excluded further argues against selection bias. ${ }^{10}{ }^{15}$ In pancreatic and other cancers selection biases are proving to be particularly difficult to overcome by studies using biomarkers of environmental exposures and genetic information. ${ }^{54} 73$

Our study did not directly estimate the effects of food and nutrient intakes on the risk of pancreatic cancer, as many other studies have done; ${ }^{5-9}$ no such studies assessed gene/environment interactions. Indeed, outside colorectal neoplasms ${ }^{19-26}$ it is still fairly exceptional to find case-case-control studies assessing gene/environment interactions and relatively free from selection and information bias (that is, including a large proportion of the original incident cases in analyses that involve genes, biomarkers of environmental exposures, clinical information, and data from patient interviews). Retrieving tumour DNA from hospitals seems a major obstacle. ${ }^{1}$
In addition to chance, several methodological features may have influenced results. The brief questionnaire clearly presented a limited ability to disaggregate higher intakes of some food groups, such as milk and other dairy products, fresh vegetables, bread and fruit. We did not pretend that the correlation with simulated intake would be a validation study for the bFFQ. ${ }^{28}$ Rather, with that exercise we tried to assess whether the bFFQ was an acceptable instrument to classify participants according to food and nutrient intakes, including energy intake. By assuming that specific food intakes from a nutritional survey carried out with a similar population of the same region could be applied to our study population, we observed plausible values for food and nutrient intakes that we considered good enough to classify participants with an acceptable degree of certainty. ${ }^{28}$ Despite its limitations the questionnaire seemed useful to identify subjects with very low intakes of the above-mentioned food groups and related nutrients. Some nutrient intakes may have been underestimated, and a certain degree of misclassification is inevitable when assessing diet in patients who are severely ill. ${ }^{28} 30$ Furthermore, misclassification was most likely non-differential with respect to K-ras status; hence, better dietary measurements seem more likely to reveal stronger than weaker associations.

In conclusion, exposure to specific dietary components or contaminants could contribute to the occurrence or persistence of K-ras mutations in human exocrine pancreatic cancer. Findings might have implications as well for other neoplasms with a high frequency of mutations in the K-ras oncogene (for example, colon and lung adenocarcinomas). Nonetheless, because this is only the first study on diet and K-ras mutations in pancreatic cancer, studies free from selection and information bias, and with the power to refute or to confirm the results are required before mechanistic, clinical and public health implications_if any-are considered.

\section{ACKNOWLEDGEMENTS}

The authors gratefully acknowledge scientific and technical assistance provided by Elisa Puigdomènech, Esteve Fernàndez, Joan Alguacil, David J. MacFarlane, Isabel Egea and Silvia Geeraerd.

\section{Authors' affiliations}

E Morales, M Porta, T López, M A Mendez, J Pumarega, N Malats,

M Crous-Bou, J Ngo, F X Real, Institut Municipal d'Investigació Mèdica, Barcelona, and CIBER en Epidemiología y Salud Pública (CIBERESP), Spain 


\section{What is already known}

- Over 20 years of research have shown that ras genes can be involved in the initiation of carcinogenesis and are critical DNA targets for chemical carcinogens, and that somatic (acquired) mutations in the K-ras oncogene are an early and fundamental event in the aetiopathogenesis of exocrine pancreatic cancer.

- K-ras mutations are also common in other human cancers, as lung and colon adenocarcinomas; they are the most frequent abnormality of oncogenes in human cancer.

- Research on lifestyle and environmental influences upon the occurrence and persistence of ras mutations in humans is scant.

- Fat foods contain lipophilic environmental chemical agents, like organochlorine compounds; most human exposure to organochlorines occurs through food, including dairy products.

\section{What this paper adds}

- This is the first study on the relation between dietary factors and K-ras mutations in human exocrine pancreatic cancer. It is the largest study with molecular environmental and genetic information in this neoplasm.

- Results suggest that exposure to specific dietary components may influence the occurrence or persistence of $\mathrm{K}$ ras mutations in pancreatic cancer.

- Findings may have mechanistic implications for other neoplasms with a high frequency of K-ras mutations.

- Findings are relevant for scientists working on human carcinogenesis, diet or pancreatic cancer; they contribute to the scant literature on the role of gene/environment interactions in the poorly understood aetiopathogenesis of this lethal disease.

\section{Policy implication}

- Studies free from selection and information biases, and with the power to refute or to confirm the results are required before policy implications are considered.

J Vioque, School of Medicine, Universidad Miguel Hernández, Alacant, Spain

J Rifà, Hospital Son Dureta, Palma de Mallorca, Spain

A Carrato, Hospital Universitari d'Elx, Alacant, Spain

L Guarner, Hospital Universitari de la Vall d'Hebron, Barcelona, Spain

J M Corominas, Hospital Universitari del Mar, Barcelona, Spain

E Morales, M Porta, Preventive Medicine \& Public Health Educational Unit, UPF-IMAS-ASPB, Barcelona, Spain

M Porta, M Crous-Bou, L Guarner, J M Corominas, School of Medicine, Universitat Autònoma de Barcelona, Spain

F X Real, Universitat Pompeu Fabra, Barcelona, Spain

Supported in part by research grants from Red temática de investigación cooperativa de centros en Cáncer (C03/10), Red temática de investigación cooperativa de centros en Epidemiología y salud pública (C03/09), and CIBER de Epidemiología y Salud Pública, Instituto de Salud Carlos III; Oficina de Ciencia y Tecnología de la Generalitat Valenciana (Grupos 03/ 136); and by Departament de Salut, Generalitat de Catalunya.

\section{Competing interests: None declared.}

*Members of the Multicentre Prospective Study on the Role of K-ras and other Genetic Alterations in the Diagnosis, Prognosis and Etiology of Pancreatic and Biliary Diseases (PANKRAS II) Study Group are mentioned in previous publications.[10, 15]

\section{REFERENCES}

1 Li D, Jiao L, Porta M. Epidemiology. In: von Hoff DD, Evans DB, Hruban RH, eds. Pancreatic cancer. Boston: Jones \& Bartlett, 2005:103-117.

2 Soliman AS, Bondy $M$, Webb CR, et al. Differing molecular pathology of pancreatic adenocarcinoma in Egyptian and United States patients. Int $J$ Cancer 2006;119:1455-61

3 Porta M, Ayude D, Alguacil J, et al. Exploring environmental causes of altered ras effects: fragmentation plus integration? Mol Carcinog 2003:36:45-52.

4 Bardeesy N, DePinho RA. Pancreatic cancer biology and genetics. Nat Rev Cancer 2002;2:897-909.

5 Howe GR, Ghadirian P, Bueno de Mesquita HB, et al. A collaborative casecontrol study of nutrient intake and pancreatic cancer within the SEARCH programme. Int J Cancer 1992;51:365-72.

6 Howe GR, Burch JD. Nutrition and pancreatic cancer. Cancer Causes Control 1996;7:69-82

7 Stolzenberg-Solomon RZ, Albanes D, Nieto FJ, et al. Pancreatic cancer risk and nutrition-related methyl-group availability indicators in male smokers. J Natl Cancer Inst 1999;91:535-41.

8 Skinner HG, Michaud DS, Giovannucci E, et al. Vitamin D intake and the risk for pancreatic cancer in two cohort studies. Cancer Epidemiol Biomarkers Prev 2006; 15:1688-95

9 Stolzenberg-Solomon RZ, Vieth R, Azad A, et al. A prospective nested casecontrol study of vitamin $D$ status and pancreatic cancer risk in male smokers. Cancer Res 2006:66:10213-9.

10 Porta M, Malats N, Jariod M, et al. Serum concentrations of organochlorine compounds and K-ras mutations in exocrine pancreatic cancer. Lancet 1999;354:2125-9.

11 Real FX. The cell biology of pancreatic cancer. In: Neoptolemos J, Lemoine NR, eds. Pancreatic cancer.Molecular and clinical advances. London: Blackwell, 1995:3-17.

12 Malumbres M, Barbacid M. RAS oncogenes: the first 30 years. Nat Rev Cancer 2003;3:459-65.

13 Shields JM, Pruitt K, McFall A, et al. Understanding Ras: "it ain't over 'til it's over". Trends Cell Biol 2000;10:147-54.

14 Alguacil J, Porta M, Malats $N$, et al. Occupational exposure to organic solvents and $\mathrm{K}$-ras mutations in exocrine pancreatic cancer. Carcinogenesis 2002;23:101-6.

15 Porta M, Malats N, Guarner L, et al. Association between coffee drinking and K ras mutations in exocrine pancreatic cancer. J Epidemiol Community Health 1999:53:702-9.

16 Porta M, Malats N, Alguacil J, et al. Coffee, pancreatic cancer, and K-ras mutations: updating the research agenda. J Epidemiol Community Health 2000;54:656-9.

17 Slebos RJ, Hoppin JA, Tolbert PE, et al. K-ras and p53 in pancreatic cancer: association with medical history, histopathology, and environmental exposures in a population-based study. Cancer Epidemiol Biomark Prev 2000;9:1223-32.

18 Jacobsen BK, Heuch I. Coffee, K-ras mutations and pancreatic cancer: a heterogeneous aetiology or an artefact? J Epidemiol Community Health 2000;54:654-5.

19 Bautista D, Obrador A, Moreno V, et al. Ki-ras mutation modifies the protective effect of dietary monounsaturated fat and calcium on sporadic colorectal cancer. Cancer Epidemiol Biomarkers Prev 1997;6:57-61

20 Kampman E, Voskuil DW, van Kraats AA, et al. Animal products and K-ras codon 12 and 13 mutations in colon carcinomas. Carcinogenesis 2000;21:307-9.

21 Slattery ML, Curtin K, Anderson K, et al. Associations between dietary intake and Ki-ras mutations in colon tumors: a population-based study. Cancer Res 2000;60:6935-41

22 Laso N, Mas S, Lafuente JM, et al. Decrease in specific micronutrient intake in colorectal cancer patients with tumors presenting Ki-ras mutation. Anticancer Res 2004;24:201 1-20

23 Brink M, Weijenberg MP, de Goeij AF, et al. Dietary folate intake and k-ras mutations in sporadic colon and rectal cancer in The Netherlands Cohort Study. Int J Cancer 2005:114:824-30.

24 Brink M, Weijenberg MP, de Goeij AF, et al. Meat consumption and K-ras mutations in sporadic colon and rectal cancer in The Netherlands Cohort Study. Br J Cancer 2005:92:1310-20.

25 Martinez ME, Maltzman T, Marshall JR, et al. Risk factors for Ki-ras protooncogene mutation in sporadic colorectal adenomas. Cancer Res 1999;59:5181-5.

26 Wark PA, Van der Kuil W, Ploemacher J, et al. Diet, lifestyle and risk of K-ras mutation-positive and -negative colorectal adenomas. Int $J$ Cancer 2006; 119:398-405.

27 Yano T, Uchida M, Yuasa M, et al. The inhibitory effect of vitamin E on K-ras mutation at an early stage of lung carcinogenesis in mice. Eur J Pharmacol 1997;323:99-102. 
28 Mendez MA, Vioque J, Porta $M$, et al. Estimating dietary intakes from a brief questionnaire: A simulation study of reliability in a molecular epidemiologic study of pancreatic and biliary diseases. Eur J Epidemiol 2006;21:417-26.

29 Porta M, Fabregat X, Malats N, et al. Exocrine pancreatic cancer: symptoms at presentation and their relation to tumour site and stage. Clin Transl Oncol 2005:7:189-97.

30 Gavaldà L, Porta $M$, Malats N, et al. Concordancia entre la información facilitada por el paciente y un familiar sobre antecedentes patológicos, consumo de tabaco, de alcohol, de café, y dieta en el cáncer de páncreas exocrino y del sistema biliar extrahepático. Gac Sanit 1995;9:334-42.

31 Vioque J, González L. Validity of a food frequency questionnaire. Preliminary results. Eur J Cancer Prev 1991;1:19-20.

32 Rosenbaum PR. The case-only odds ratio as a causal parameter. Biometrics 2004;60:233-40.

33 Willett WC, Stampfer M. Implications of total energy intake for epidemiologic analyses. In: Willett WC, eds. Nutritional epidemiology. 2nd ed. New York: Oxford University Press, 1998:273-301

34 Armitage P, Berry G, Matthews JNS. Statistical methods in medical research. 4th edn. Oxford: Blackwell, 2002.

35 Kleinbaum DG, Kupper LL, Morgenstern H. Epidemiologic research. Belmont, CA: Lifetime Learning Publications, 1982;320-76,343,419-56.

36 Breslow NE, Day NE. Statistical methods in cancer research. Vol I: The analysis of case-control studies. Lyon: IARC Scientific Publications, 1980:149-54.

37 Porta $M$, Jariod M, López $T$, et al. In pancreatic ductal adenocarcinoma coffee intake and serum concentrations of some organochlorine compounds are independently associated with the mutational activation of the K-ras oncogene [abstract]. Fifth AACR International Conference on Frontiers in Cancer Prevention Research (Boston, Nov. 12-15, 2006). AACR Meeting Abstracts;2006:A187. Available from http://www.aacrmeetingabstracts.org/ [date accessed 3 March 2007].

38 Stolzenberg-Solomon RZ, Pietinen P, Taylor PR, et al. Prospective study of die and pancreatic cancer in male smokers. Am J Epidemiol 2002;155:783-92.

39 Falk RT, Pickle LW, Fontham ET, et al. Life-style risk factors for pancreatic cancer in Lovisiana: a case-control study. Am J Epidemiol 1988;128:324-36.

40 Michaud DS, Giovannucci E, Willett WC, et al. Dietary meat, dairy products, fat, and cholesterol and pancreatic cancer risk in a prospective study. Am J Epidemiol 2003; 157:1 1115-25.

41 Nöthlings U, Wilkens LR, Murphy SP, et al. Meat and fat intake as risk factors for pancreatic cancer: the multiethnic cohort study. I Natl Cancer Inst 2005;97:1458-65.

42 Institute of Medicine. Dioxins and dioxin-like compounds in the food supply Strategies to decrease exposure. Washington, DC: The National Academies Press, 2003.

43 Kalantzi OI, Alcock RE, Johnston PA, et al. The global distribution of PCBs and organochlorine pesticides in butter. Environ Sci Technol 2001;35:1013-8.

44 Weiss J, Papke O, Bergman A. A worldwide survey of polychlorinated dibenzop-dioxins, dibenzofurans, and related contaminants in butter. Ambio 2005:34:589-97.

45 Santillo D, Fernandes A, Stringer R, et al. Butter as an indicator of regional persistent organic pollutant contamination: further development of the approach using polychlorinated dioxins and furans ( $P C D D / F s)$, and dioxin-like polychlorinated biphenyls (PCBs). Food Addit Contam 2003;20:281-90.

46 Badia-Vila M, Ociepa M, Mateo R, et al. Comparison of residue levels of persistent organochlorine compounds in butter from Spain and from other European countries. J Environ Sci Health B 2000;35:201-10.

47 Abad E, Llerena JJ, Saulo J, et al. Study on PCDDs/PCDFs and co-PCBs content in food samples from Catalonia (Spain). Chemosphere 2002;46:1435-41.

48 Eljarrat E, Monjonell A, Caixach J, et al. Toxic potency of polychlorinated dibenzo-p-dioxins, polychlorinated dibenzofurans, and polychlorinated biphenyls in food samples from Catalonia (Spain). J Agric Food Chemistry 2002;50:1161-7.

49 Bocio A, Domingo JL. Daily intake of polychlorinated dibenzo-p-dioxins/ polychlorinated dibenzofurans (PCDD/PCDFs) in foodstuffs consumed in Tarragona, Spain: a review of recent studies (2001-2003) on human PCDD/ PCDF exposure through the diet. Environ Res 2005;97:1-9.
50 Schafer KS, Kegley SE. Persistent toxic chemicals in the food supply. J Epidemiol Community Health 2002;56:813-7.

51 Ribas-Fitó N, Torrent $M$, Carrizo D, et al. In utero exposure to background concentrations of DDT and cognitive functioning among preschoolers. Am J Epidemiol 2006;164:955-62.

52 Carreño J, Rivas A, Granada A, et al. Exposure of young men to organochlorine pesticides in Southern Spain. Environ Res 2007;103:55-61.

53 Hoppin JA, Tolbert PE, Holly EA, et al. Pancreatic cancer and serum organochlorine levels. Cancer Epidemiol Biomark Prev 2000;9:199-205.

54 Porta M, Malats N, Vioque J, et al. Incomplete overlapping of biological, clinical and environmental information in molecular epidemiologic studies: a variety of causes and a cascade of consequences. J Epidemiol Community Health 2002;56:734-8

55 Kuper HE, Mucci LA, Trichopoulos D. Coffee, pancreatic cancer and the question of causation. J Epidemiol Community Health 2000;54:650-51.

56 Vineis P. ras mutations and a cup of coffee: cause, confounder, effect modifier, or what else? [editorial]. J Epidemiol Community Health 1999;53:685.

57 Vineis P. Exposures, mutations and the history of causality. J Epidemiol Community Health 2000;54:652-3.

58 Porta M, Viogue J, Ayude D, et al. Coffee drinking: The rationale for treating it as a potential effect modifier of carcinogenic exposures. Eur J Epidemiol 2003; 18:289-98.

59 Luch A. Nature and nurture. Lessons from chemical carcinogenesis. Nat Rev Cancer 2005:5:113-25.

60 Kakiuchi H, Ushijima T, Ochiai M, et al. Rare frequency of activation of the Ki-ras gene in rat colon tumors induced by heterocyclic amines: possible alternative mechanisms of human colon carcinogenesis. Mol Carcinog 1993;8:44-8.

61 Toyota M, Ushiiima T, Kakiuchi $\mathrm{H}$, et al. Genetic alterations in rat colon tumors induced by heterocyclic amines. Cancer 1996;77(8 Suppl):1593-7.

62 Ushijima T, Kakiuchi H, Makino H, et al. Infrequent mutation of Ha-ras and p53 in rat mammary carcinomas induced by by 2-amino-1-methyl-6phenylimidazo[4,5-b]pyridine. Mol Carcinog 1994;10:38-44.

63 Hass BS, Hart RW, Lu MH, et al. Effects of caloric restriction in animals on cellular function, oncogene expression, and DNA methylation in vitro. Mutat Res 1993;295:281-9.

64 Fernandes G, Chandrasekar B, Troyer DA, et al. Dietary lipids and calorie restriction affect mammary tumor incidence and gene expression in mouse mammary tumor virus/v-Ha-ras transgenic mice. Proc Natl Acad Sci USA 1995;92:6494-8

65 Fujii $\mathrm{H}$, Egami $\mathrm{H}$, Chaney W, et al. Pancreatic ductal adenocarcinomas induced in Syrian hamsters by $\mathrm{N}$-nitrosobis(2-oxopropyl)amine contain a c-Ki-ras oncogene with a point-mutated codon 12. Mol Carcinog 1990;3:296-301.

66 Roebuck BD. Dietary fat and the development of pancreatic cancer. Lipids 1992;27:804-6.

67 Woutersen RA, Appel MJ, van Garderen-Hoetmer A, et al. Dietary fat and carcinogenesis. Mutat Res 1999;443:111-27.

68 Collett ED, Davidson LA, Fan YY, et al. n-6 and n-3 polyunsaturated fatty acids differentially modulate oncogenic Ras activation in colonocytes. Am J Physiol Cell Physiol 2001;280:C1066-75.

69 Liu G, Bibus DM, Bode AM, et al. Omega 3 but not omega 6 fatty acids inhibit AP-1 activity and cell transformation in JB6 cells. Proc Natl Acad Sci USA 2001;98:7510-5.

70 Singh J, Hamid R, Reddy BS. Dietary fat and colon cancer: modulating effect of types and amount of dietary fat on ras-p21 function during promotion and progression stages of colon cancer. Cancer Res 1997;57:253-8.

71 Roynette CE, Calder PC, Dupertuis YM, et al. n-3 polyunsaturated fatty acids and colon cancer prevention. Clin Nutr 2004;23:139-51

72 Larsson SC, Kumlin M, Ingelman-Sundberg M, et al. Dietary long-chain n-3 fatty acids for the prevention of cancer: a review of potential mechanisms. Am J Clin Nutr 2004;79:935-45.

73 Porta M, Malats N, Corominas JM, et al. Generalizing molecular results arising from incomplete biological samples: expected bias and unexpected findings. Ann Epidemiol 2002;12:7-14. 